(falling). This process occurs in diverse conditions, some physiological, such as in embryonic development and involutional processes; and others pathological, as in immune mediated cell killing, and ischaemic injury. In their review article Nicholas D Mazarakis and colleagues (see p F165) highlight the broad spectrum of neurological disorders where apoptosis is a feature, including hypoxicischaemic brain injury in the newborn. The importance of learning more about this form of cell death is that if effective antiapoptotic strategies were available they would be potentially applicable to a wide range of disorders.

If, as we have seen, fetal nutrition influences health in adulthood it is reasonable to ask to what extent aging, in this context biological senescence, occurs in the placenta. This subject is reviewed by Harold Fox (see pF171) who indicates that, far from senescence, the term placenta shows continuing DNA synthesis, and persisting villous growth and expansion of villous surface area. He refutes the widely held notion that, come 40 weeks' gestation, the placenta goes into a decline, both functionally and anatomically. Indeed, he draws attention to fetal macrosomia in prolonged pregnancy. $\mathrm{He}$ argues that the classical clinical syndrome of 'postmaturity' (now uncommon) is related to oligohydramnios, for which the placenta should not take the blame as there is no evidence that in late pregnancy it has a role in the production of amniotic fluid, or in the control of its volume.

In conclusion, high quality epidemiological research during the next decade will present us with many intriguing discoveries about the influence of fetal and early childhood experience on diseases in adult life. We need also to tease out similarities of biological mechanisms of disease processes in the young and the elderly. Treatment strategies aimed at manipulating biological processes may be common to both. Stroke in the elderly and hypoxicischaemic brain damage in the newborn is but one example. We should also acknowledge the notion that 'dependency' provokes similar psychosocial problems at the two extremes of life including neglect and abuse. The basic science that governs the state of dependency of the very young and the elderly has similarities that might be exploited to provide improved preventive and management strategies for both, even though there will be differences in detail.

\title{
Child to adult body mass index in the 1958 British birth cohort: associations with parental obesity
}

\author{
Julie K Lake, Chris Power, Tim J Cole
}

\section{Department of Epidemiology and Public Health, Institute of Child Health, 30 Guilford Street, London WC1N 1EH \\ J K Lake \\ C Power}

MRC Dunn Nutrition Unit, Cambridge T J Cole

Correspondence to: J K Lake.

\begin{abstract}
Objectives-To assess relations between the adiposity of children and their parents and to establish whether tracking of adiposity from childhood to adulthood varies according to the parental body mass index (BMI).

Methods-Longitudinal data from the 1958

British birth cohort study were used (6540 men and 6207 women). The height and weight of the study subjects were measured at $7,11,16,23$ (self reported), and 33 years. Parental height and weight were self reported when their children were 11 years old. The children were classified into six parental BMI (weight/height ${ }^{2}$ ) groups.

Results-At each age of follow up the mean BMI of the children increased as the parental BMI increased. Higher risks of adult (33 year) obesity were evident among children with overweight or obese parents: the odds for sons and daughters with two obese parents (compared with those with both parents of normal BMI)
\end{abstract}

were 8.4 and 6.8 , respectively. The children of two obese parents also showed the strongest child to adult tracking of BMI as indicated by the correlation between ages 7 and $33(r=0.46,0.54$, sons and daughters, respectively).

Conclusions-The children of obese and overweight parents have an increased risk of obesity. Subjects with two obese parents are fatter in childhood and also show a stronger pattern of tracking from childhood to adulthood. As the prevalence of parental obesity increases in the general population the extent of child to adult tracking of BMI is likely to strengthen. (Arch Dis Child 1997;77:376-381)

Keywords: body mass index; child to adult tracking; obesity; parent

Obesity is a common nutritional disorder and is an important risk factor for several chronic diseases. ${ }^{12}$ Thus factors influencing the 
Table 1 BMI groups (cut offs, percentages, and numbers) for mothers and fathers of the 1958 birth cohort

\begin{tabular}{llllll}
\hline & \multicolumn{2}{l}{ Father } & & \multicolumn{2}{l}{ Mother } \\
\cline { 2 - 2 } \cline { 5 - 6 } & Cut off & No $(\%)(n=12948)$ & & Cut off & No (\%) $(n=13368)$ \\
\hline Underweight & $<20.0$ & $504(3.9)$ & & $<18.7$ & $749(5.6)$ \\
Normal weight & $\geqslant 20.0$ and $\leqslant 24.9$ & $6933(53.5)$ & & $\geqslant 18.7$ and $\leqslant 23.7$ & $6555(49.0)$ \\
Overweight & $>24.9$ and $\leqslant 27.7$ & $3555(27.5)$ & & $>23.7$ and $\leqslant 27.6$ & $3982(29.8)$ \\
Obese $^{\star}$ & $>27.7$ & $1956(15.1)$ & & $>27.6$ & $2082(15.6)$ \\
\hline
\end{tabular}

* Defined by the 85 th centile.

development of obesity have been sought with the aim of identifying appropriate prevention strategies. Among factors linked to obesity in childhood and adolescence are parental obesity, ${ }^{3-13}$ poor paternal education, ${ }^{14}$ parental neglect, ${ }_{15}^{15}$ poor quality housing, ${ }^{16}$ learning difficulties, ${ }^{17}$ minority ethnicity, ${ }^{318}$ fewer siblings, ${ }^{19} 20$ excessive television viewing, ${ }^{21-24}$ a high protein intake in infancy, ${ }^{25}$ and short sleep duration. ${ }^{21}$ Parental obesity has been identified as a predominant risk factor, with childhood fatness increasing linearly with an increasing level of parental fatness. ${ }^{34910}$ Children with two obese parents have higher risks of obesity than those with one or neither parent obese. ${ }^{36}$ Some studies suggest differential effects of maternal and paternal obesity, ${ }^{1026}$ but this is not a consistent finding. ${ }^{3}{ }^{71}{ }^{12}$ Parent-child adiposity correlations also appear to increase with the age of the child. ${ }^{3}$

Most studies of parental obesity have been cross sectional, however, in that childhood data are available for only one age. Consequently, it is not known whether parental obesity affects the child-adult adiposity trajectory of their offspring. Published data on the tracking of adiposity from childhood to adulthood, although extensive, does not address this issue, but it does show a moderate relation between early and adult life. ${ }^{27}{ }^{28}$ The purpose of this study was to assess relations between the adiposity of children and their parents and to establish whether the tracking of adiposity from childhood to adulthood varies according to parental obesity status. We used data from the 1958 British birth cohort study, a longitudinal sample for which we have previously reported child-adult associations for body mass index (BMI) and height. ${ }^{29}$

\section{Subjects and methods}

SAMPLE

The 1958 British birth cohort study includes all children born in Scotland, Wales, and England between 3 and 9 March $1958 .^{30}$ From a target population of 17733 births, information was obtained on $98 \%$. Major follow ups of sur- viving children were conducted at the ages of 7 , $11,16,23$, and 33 years. ${ }^{31}$ Immigrants to Britain born during the same week in 1958 were incorporated into the survey at ages 7,11 , and 16. Sample attrition has occurred, but despite this the representativeness of the study has been maintained, in general, through to the age of 33 years, when 11407 subjects ( $69 \%$ of the target population) provided information. There is some evidence to suggest a slight under representation of 'disadvantaged' subjects. ${ }^{31}$ Information at ages 23 and 33 years was obtained through an interview with the study subjects. Previous sweeps collected data from several sources, including parents and schools (teachers and doctors), as well as from the individual subjects.

\section{MEASURES}

The heights and weights of the cohort members (the offspring) were measured by trained medical staff at 7,11 , and 16 years. The subjects were weighed in their underclothes to the nearest pound, and their height was measured to the nearest inch. Self reports of height and weight were obtained at the age of 23 years and were checked to detect coding errors. ${ }^{32}$ These self reports are in agreement with the measured heights in a national sample of British adults surveyed in $1980 .{ }^{33}$ At the age of 33 years, heights were measured without shoes using a stadiometer reading to the nearest centimetre, and weights were measured in indoor clothing using Salter portable scales. The dates of measurement were recorded at the ages of 7 , 11 , and 16 years.

The heights and weights of the parents were self reported when their children were aged 11 years in 1969. Heights were reported to the nearest inch; weights were classified into one of 27 groups ranging from 6 stone 4 pounds $(39.9$ $\mathrm{kg})$ to 19 stone 10 pounds $(125.2 \mathrm{~kg})$ in increments of 6 pounds $(2.7 \mathrm{~kg})$. For the purpose of estimating Quetelet's BMI (defined as weight/ height $^{2}$ ), the parents were assigned a weight equivalent to the midpoint of their weight group. The BMI was calculated at a single time

Table 2 No (\%) and means in the six parental BMI groups

\begin{tabular}{|c|c|c|c|c|c|c|}
\hline \multirow[b]{3}{*}{ Parental BMI groups } & \multicolumn{3}{|l|}{ Sons } & \multicolumn{3}{|l|}{ Daughters } \\
\hline & \multirow[b]{2}{*}{ No $(\%)(n=6540)$} & \multicolumn{2}{|c|}{ Mean BMI } & \multirow[b]{2}{*}{ No $(\%)(n=6207)$} & \multicolumn{2}{|c|}{ Mean BMI } \\
\hline & & Father & Mother & & Father & Mother \\
\hline One underweight & $481(7.4)$ & 21.9 & 19.5 & $486(7.8)$ & 21.6 & 19.7 \\
\hline Both normal & $1844(28.2)$ & 22.9 & 21.6 & $1781(28.7)$ & 22.9 & 21.5 \\
\hline One overweight & $1807(27.6)$ & 24.5 & 23.5 & $1723(27.8)$ & 24.4 & 23.6 \\
\hline Both overweight & $583(8.9)$ & 26.2 & 25.3 & $545(8.8)$ & 26.2 & 25.3 \\
\hline One obese & $1609(24.6)$ & 26.7 & 27.0 & $1482(23.9)$ & 26.9 & 26.7 \\
\hline Both obese & $216(3.3)$ & 30.4 & 31.4 & $190(3.1)$ & 30.4 & 31.3 \\
\hline
\end{tabular}


Table 3 Parental BMI groups and mean BMI (number of subjects) of offspring at five ages (7 to 33 years)

\begin{tabular}{|c|c|c|c|c|c|c|}
\hline \multirow[b]{2}{*}{ Age of offspring } & \multicolumn{6}{|c|}{ Parental BMI group } \\
\hline & One underweight & Both normal & One overweight & Both overweight & One obese & Both obese \\
\hline \multicolumn{7}{|l|}{7 years } \\
\hline Sons & $15.5(404)$ & $15.7(1532)$ & $15.9(1512)$ & $16.2(491)$ & $16.2(1323)$ & $17.0(181)$ \\
\hline Daughters & $15.3(408)$ & $15.5(1463)$ & $15.8(1429)$ & $16.2(461)$ & $16.2(1210)$ & $17.0(150)$ \\
\hline \multicolumn{7}{|l|}{11 years } \\
\hline Sons & $16.4(428)$ & $16.7(1650)$ & $17.2(1625)$ & $17.9(529)$ & $17.9(1447)$ & $18.8(188)$ \\
\hline Daughters & $16.6(443)$ & $17.0(1613)$ & $17.6(1563)$ & $18.1(499)$ & $18.4(1336)$ & $19.7(167)$ \\
\hline \multicolumn{7}{|l|}{16 years } \\
\hline Sons & $19.2(336)$ & $19.6(1306)$ & $20.2(1242)$ & $20.8(418)$ & $20.9(1085)$ & $22.4(146)$ \\
\hline Daughters & $20.0(330)$ & $20.3(1237)$ & $21.0(1211)$ & $21.5(369)$ & $21.8(1019)$ & $23.8(127)$ \\
\hline \multicolumn{7}{|l|}{23 years } \\
\hline Sons & $22.2(345)$ & $22.2(1360)$ & $23.0(1360)$ & $23.5(447)$ & $23.9(1179)$ & $25.3(156)$ \\
\hline Daughters & $21.1(383)$ & $21.3(1401)$ & $22.0(1363)$ & $22.6(421)$ & $22.9(1147)$ & $25.0(151)$ \\
\hline \multicolumn{7}{|l|}{33 years } \\
\hline Sons & $24.2(313)$ & $24.6(1274)$ & $25.6(1167)$ & $26.4(406)$ & $26.5(1023)$ & $28.5(146)$ \\
\hline Daughters & $23.2(349)$ & $23.5(1280)$ & $24.4(1240)$ & $25.6(379)$ & $25.8(1042)$ & $28.3(137)$ \\
\hline
\end{tabular}

for the parents (that is, when their children were aged 11 years) and at each of the five ages of follow up for the children. Parental BMI was first classified as underweight, normal, overweight, or obese, as defined by the 85 th centile (see table 1 for cut offs). This particular cut off corresponds to the centile used to define obesity in the USA, ${ }^{34}$ although the definition is arbitrary and other centiles have been suggested. ${ }^{28}$ The 85 th centile ensured adequate sample sizes in the obese groups. Six parental obesity groups were then constructed (the abbreviated names of these groups are given in quotes and these are used throughout this paper). These are ordered in increasing parental fatness based on the combination of the mother's and father's mean BMI (see table 2 for means): (a) 'one underweight'-one parent underweight, one not obese (that is, underweight, normal, or overweight); (b) 'both normal'-both parents of normal BMI; (c) 'one overweight' - one parent overweight, one of normal BMI; (d) 'both overweight'-both parents overweight; (e) 'one obese'-one parent obese, one not obese (that is, underweight, normal, or overweight); and (f) 'both obese'both parents obese.

STATISTICAL METHODS

The relation between the BMI of the parents and their offspring was assessed using partial correlation coefficients, adjusted for measurement date in childhood, at ages $7,11,16,23$, and 33 years. To investigate the tracking of adiposity from child to adult life, in relation to parental obesity status, partial correlation coefficients were then calculated between the child's BMI at ages 7 and 33 years (adjusted for measurement date at age 7 years) separately for each of the six parental obesity groups.
To reduce the skewness of the BMI distributions, correlations were also calculated using $\log _{\mathrm{e}}(\mathrm{BMI})$ and $-1 / \mathrm{BMI}$. Trivial differences $(-0.06$ to 0.03$)$ were found between correlations using transformed and not transformed BMIs, so only the latter are presented. Differences in the correlation coefficients (ages 7 and 33 years) between parental obesity groups were tested using Fisher's transformation. ${ }^{35}$

\section{Results}

Table 1 shows that approximately $50 \%$ of parents had BMIs in the normal range and, as predetermined by the definition of parental obesity, approximately $15 \%$ were obese. About $3 \%$ of the children had two obese parents, $9 \%$ had two who were overweight, and over a quarter had two parents of normal BMI (table 2). In general, the mean BMIs were similar for children with either an underweight, overweight, or obese mother or father, so these are combined and reported as the one underweight, one overweight, or one obese parent groups, respectively.

Table 3 shows that, in general, the mean BMI of the children increases as the degree of parental fatness increases. This is consistent for sons and daughters at each age from 7 to 33 years. The largest difference between adjacent groups in mean BMI was for those with both parents obese compared with those with one obese (range 0.8 to $2.5 \mathrm{~kg} / \mathrm{m}^{2}$ ). The smallest difference was found between children with one underweight parent compared with both with normal BMI (range 0.2 to $0.4 \mathrm{~kg} / \mathrm{m}^{2}$ ). Differences in mean BMI increased with increasing age of the child-for example, 7 year old daughters with two obese parents had a mean BMI 9.7\% greater than those with two

Table 4 Odds ratios of obesity in offspring at age 33 years for parental BMI groups

\begin{tabular}{|c|c|c|c|c|}
\hline \multirow[b]{2}{*}{ Parental BMI groups } & \multicolumn{2}{|l|}{ Sons } & \multicolumn{2}{|l|}{ Daughters } \\
\hline & Odds ratio & $\begin{array}{l}95 \% \text { Confidence } \\
\text { interval }\end{array}$ & Odds ratio & $\begin{array}{l}95 \% \text { Confidence } \\
\text { interval }\end{array}$ \\
\hline One underweight & 1.29 & 0.77 to 2.17 & 0.95 & 0.63 to 1.44 \\
\hline Both normal ${ }^{\star}$ & 1 & - & 1 & - \\
\hline One overweight & 1.99 & 1.45 to 2.73 & 1.47 & 1.14 to 1.88 \\
\hline Both overweight & 3.41 & 2.36 to 4.93 & 2.65 & 1.95 to 3.62 \\
\hline One obese & 3.43 & 2.53 to 4.64 & 2.98 & 2.35 to 3.78 \\
\hline Both obese & 8.42 & 5.47 to 13.00 & 6.75 & 4.57 to 9.96 \\
\hline
\end{tabular}

^ Baseline group: two normal BMI parents. 
Table 5 Partial BMI correlations between parents and offspring at five ages ( 7 to 33 years). Adjusted for date of measurement of offspring at ages 7, 11, and 16

\begin{tabular}{lll}
\hline & \multicolumn{2}{l}{ Correlation (No of subjects) } \\
\cline { 2 - 3 } Age of offspring & Father & Mother \\
\hline 7 years & & \\
$\quad$ Sons & $0.15(5513)$ & $0.16(5658)$ \\
$\quad \begin{array}{l}\text { Daughters } \\
11 \text { years }\end{array}$ & $0.15(5177)$ & $0.15(5353)$ \\
$\quad$ Sons & $0.18(5966)$ & $0.23(6126)$ \\
$\quad \begin{array}{l}\text { Daughters } \\
\text { 16 years }\end{array}$ & $0.17(5695)$ & $0.25(5898)$ \\
$\quad$ Sons & $0.20(4611)$ & $0.22(4727)$ \\
$\quad \begin{array}{l}\text { Daughters } \\
\text { 23 years }\end{array}$ & $0.20(4350)$ & $0.23(4512)$ \\
$\quad$ Sons & $0.21(4924)$ & $0.24(5030)$ \\
$\quad \begin{array}{l}\text { Daughters } \\
\text { 33 years }\end{array}$ & $0.17(4943)$ & $0.25(5087)$ \\
$\quad$ Sons & $0.20(4403)$ & $0.21(4496)$ \\
Daughters & $0.15(4491)$ & $0.24(4644)$ \\
\hline
\end{tabular}

Table 6 Partial correlations between ages 7 and 33 for parental BMI groups. Adjusted for date of measurement of offspring at age 7 years

Correlation (No of subjects) between age 7 and 33 years

\begin{tabular}{lll}
\hline & \multicolumn{2}{l}{$\begin{array}{l}\text { Correlation (No of subjects) between } \\
\text { age 7 and 33 years }\end{array}$} \\
\cline { 2 - 3 } Parental BMI groups & Sons & Daughters \\
\hline One underweight & $0.19(263)$ & $0.38(297)$ \\
Both normal & $0.25(1075)$ & $0.32(1062)$ \\
One overweight & $0.33(999)$ & $0.34(1045)$ \\
Both overweight & $0.37(350)$ & $0.29(322)$ \\
One obese & $0.29(858)$ & $0.29(865)$ \\
Both obese & $0.46(125)$ & $0.54(114)$ \\
\hline
\end{tabular}

normal BMI parents and this difference increased to $20.4 \%$ at the age of 33 years. To some extent the mean BMIs underplay large differences in the risk of adult obesity at the age of 33 years for those with obese or overweight parents. The odds ratios for men and women with two obese parents (relative to those with normal BMI parents) were 8.4 (95\% confidence interval 5.5 to 13.0 ) and 6.8 (4.6 to 10.0), respectively (table 4 ).

Table 5 shows further the association between parental BMI and that of their children. This shows weak correlations, ranging from 0.15 to 0.25 at the different ages of the children. From the age of 11 years onwards, the daughters' BMI was more strongly correlated with the BMI of their mother than with their father. A similar, but weaker, pattern was evident for the sons. Correlations with mothers' BMI was similar for sons and daughters at all ages, but the father-son correlations in adulthood were significantly stronger than those for father-daughter $(\mathrm{p}<0.05)$.

Table 6 shows the extent of tracking between childhood and adulthood for the children according to parental BMI. It presents correlations of offspring BMI between the ages of 7 and 33 years for each of the six parental BMI groups. In general, daughters have slightly stronger BMI correlations than sons. Long term associations, denoted by the 7 to 33 year correlation, tend to be moderate and similar for those with both parents with normal BMI (0.25 for sons, 0.32 for daughters). Child to adult correlations are strongest for both sons and daughters with two obese parents $(0.46$ for sons, 0.54 for daughters) and differ signifi- cantly from the group with two normal BMI parents.

\section{Discussion}

Most investigations of the tracking of BMI from childhood to adulthood report only weak to moderate associations. ${ }^{27}{ }^{28}$ This is apparent from the literature review of Serdula et al. ${ }^{27}$ In agreement with this, we reported elsewhere for this large nationally representative birth cohort sample that associations between child and adult BMI were only moderate $(r=0.33$ for men and $r=0.37$ for women). ${ }^{29}$ Thus it is no surprise that in the present analyses child to adult BMI correlations are low to moderate for the $28 \%$ of subjects whose parents are both within the normal BMI category (correlation coefficients between ages 7 and 33 years, $r=$ $0.25,0.32$, sons and daughters, respectively). For the smaller percentage $(3 \%)$ with both parents obese, however, the associations between child and adult BMI were considerably stronger $(r=0.46,0.54$, sons and daughters, respectively). This suggests that, compared with those with parents in the other parental obesity groups, the prediction of adult BMI from that in childhood is much better for children with two obese parents and that the stronger tracking of BMI over the life course indicates less variable BMIs among these children. Thus we would expect the fattest children to be more likely to stay in the upper BMI centiles throughout life (indicated by the stronger correlation between BMI at 7 and 33 years). Subjects with one obese parent resembled those with two parents with normal BMI showing a weaker child to adult BMI relation, although at each age their mean BMI was intermediate between those with two normal BMI parents and those with two obese parents. It is, of course, well known that parental adiposity is related to that of their offspring, ${ }^{3-13}$ but the extent to which parental obesity influences the BMI trajectory of their children does not appear to have been documented previously.

The stronger BMI child to adult correlation observed here for the group with obese parents has important implications. When the prevalence of parental obesity is relatively low, as in the present study, the overall trend is dominated by the moderate correlations of the normal BMI groups. Under these circumstances the identification and prevention of childhood fatness may not be seen as an important strategy for the prevention of adult obesity. When the prevalence of obesity among parents increases, however, as is now happening in several developed countries, ${ }^{36-40}$ then the pattern of tracking from childhood to adulthood will be more influenced by the stronger child-adult relations shown here for those with obese parents. Using a standard definition for parents and their offspring at the age of 33 years, it is estimated that the prevalence of two obese parents in the 1958 cohort has doubled from 1969 to 1991 (3.2 to $6.0 \%$ ). Thus the child to adult tracking of BMI is likely to strengthen in the next generation - that is, among the offspring of 1958 birth cohort members. 
Only one other study was found that provided information on the tracking of the child's BMI in relation to parental fatness with which the present study can be compared. Charney et al showed that of the fattest $25 \%$ of infants (based on their weight status at 6 months), $51 \%$ were still overweight at the age of 20 years for those with at least one overweight parent, compared with $20 \%$ for those with neither parent overweight. ${ }^{6}$ If we compared a group of children consisting of those with at least one obese parent with those with no obese parent (that is, both with normal BMI) in the current study, we would still show stronger tracking in the former group, which is consistent with the results of Charney et al. ${ }^{6}$

There is extensive evidence showing a parent-child relation for BMI at a particular age in childhood. ${ }^{3910}$ Stunkard et al found approximately linear relations with the BMI of adult adoptees and the BMI of biological parents, but not the adoptive parents, which they attribute to a strong genetic influence. ${ }^{9}$ In the present investigation the mean BMI of the children increased linearly with the number of obese parents: 7 year old boys with parents within the normal BMI range had a mean BMI of 15.7 , increasing to 16.2 for those with one obese parent and to 17.0 for those with two obese parents. This trend strengthened slightly with increasing age. Focusing on adult obesity at the age of 33 years, the population attributable risks associated with having one obese parent were $37 \%$ and $32 \%$ for men and women, respectively, whereas the attributable risks associated with the small percentage $(3 \%)$ with both parents obese were $20 \%$ and $15 \%$ (sons and daughters, respectively). For obesity among the offspring therefore, there appears to be a substantial risk associated with parental BMI.

These risks are obscured to some extent when the overall relation between parent and child BMI is examined: in the 1958 birth cohort $2-6 \%$ of the variability in the children's $\mathrm{BMI}$ is explained by the parental BMI. Correlations reported here between child and parental BMI were weak $(r=0.15-0.25)$, as has been shown previously. ${ }^{3} 10122641$ Mother-child correlations were slightly stronger than father-child correlations. This greater influence of maternal adiposity is consistent with some studies, ${ }^{106}$ but not all. ${ }^{71012}$ In the present study the stronger maternal correlations may be due to the poorer quality of the father's height and weight data. The adequacy of the self reported parental height and weight data is a limitation in this investigation. Self reported data tends to underestimate BMI and hence obesity as height tends to be overestimated and weight underestimated. ${ }^{42}$ Thus a data validation check was undertaken for the mothers for whom measured and self reported heights were available in 1958 and 1969: the correlation was weaker than expected $(r=0.79)$ with an associated measurement error of $3 \mathrm{~cm}$. Reported parental weights are likely to be less precise, partly because they were recorded in categories with the exact weight unknown. It is unlikely, however, that the relation described here will be affected by an underestimation of the abso- lute value of the BMI because the obese group was defined using a population specific relative value, namely the 85 th BMI centile. The limitations of the self reported data do not appear to have had a major effect on the relations that are of interest because, as mentioned earlier, the parent-child correlations are consistent with other studies based on measured heights and weights. ${ }^{41}$

In conclusion, the children of obese parents are at increased risk of obesity throughout childhood and early adult life, particularly if both parents are obese. Tracking of BMI from the age of 7 to 33 years among the children with two obese parents was much stronger than for those with two parents of normal BMI, suggesting that the BMIs of this group are less variable with increasing age. At present, this stronger tracking pattern is not predominant, at least within this British population, therefore the prevention of adult obesity is not strongly influenced by the prevention of childhood fatness. ${ }^{29}$ As the prevalence of obesity increases among adults, their offspring are likely to be affected by the stronger child-adult relations shown here. In this instance, in which the prevalence of obesity is relatively high, the prevention of adult obesity may be more dependent on the identification and prevention of fatness in childhood.

The study was funded by the Medical Research Council. C P is supported by the Canadian Institute for Advanced Research as a Weston Fellow.

1 Garrow JS. Importance of obesity. BMF 1991;303:704-6. 2 James WPT. The origins and consequences of obesity. Ciba Foundation Symposium 201. Chichester: Wiley, 1996.

3 Garn SM, Clark DC. Trends in fatness and the origins of obesity. Pediatrics 1976;57:443-56.

4 Guillaume M, Lapidus L, Beckers F, Lambert A, Bjorntorp P. Familial trends of obesity through three generations: the Belgian-Luxembourg child study. Int 7 Obes 1996;19:S5-9. 5 Maffeis C, Micciolo R, Must A, Zaffanello M, Pinelli L. Parental and perinatal factors associated with childhood obesity in north-east Italy. Int f Obes 1994;18:301-5.

6 Charney E, Goodman HC, McBride M, Lyon B, Pratt R. Childhood antecedents of adult obesity. Do chubby infants become obese adults? N Engl F Med 1976;295:6-9.

7 Esposito-Del Puente A, Scalfi L, De Filippo E, et al. Familial and environmental influences on body composition and body fat distribution in childhood in southern Italy. Int $\mathcal{F}$ Obes 1994;18:596-601

8 Garn SM, Sullivan TV, Hawthorne VM. Fatness and obesity of the parents of obese individuals. Am $\mathcal{F}$ Clin Nutr 1989;50:1308-13.

9 Stunkard AJ, Sorenson TIA, Hanis C, et al. An adoption study of human obesity. $N$ Engl f Med 1986;314:193-8.

10 Keiller SM, Colley JRT, Carpenter RG. Obesity in school children and their parents. Ann Hum Biol 1979;6:443-55.

1 Price RA, Stunkard AJ, Ness R, et al. Childhood onset (age $<10)$ obesity has high familial risk. Int f Obes 1990;15:18595.

12 Ayatollahi SMT. Obesity in school children and their parents in southern Iran. Int $\mathcal{F}$ Obes 1992;16:845-50.

13 Duran-Tauleria E, Rona RJ, Chinn S. Factors associated with weight for height and skinfold thickness in British with weight for height and skinfold thickness in British
children. 7 Epidemiol Community Health 1995;49:466-73.

14 Greenlund KJ, Liu K, Dyer AR, Kiefe CI, Burke GL, Yunis C. Body mass index in young adults: associations with C. Body mass index in young adults: associations with
parental body size and education in the CARDIA study. Am f Public Health 1996;86:480-5.

15 Lissau I, Sorensen TIA. Parental neglect during childhood and increased risk of obesity in young adulthood. Lancet 1994;343:324-7.

16 Lissau-Lund-Sorensen I, Sorensen TIA. Prospective study of the influence of social factors in childhood on risk of overweight in young adulthood. Int $\mathcal{F}$ Obes 1992;16:169-75.

17 Lissau I, Sorensen TIA. School difficulties in childhood and risk of overweight in young adulthood: a ten year prospective population study. Int $\mathcal{F}$ Obes 1993;17:169-75.

18 Rona RJ, Chinn S. National study of health and growth: social and biological factors associated with weight-forheight and triceps skinfold of children from ethnic groups in England. Ann Hum Biol 1987;14:231-48.

19 Ravelli GP, Belmont L. Obesity in nineteen year old men: family size and birth order associations. Am f Epidemiol 1979;109:66-70. 
20 Rona RJ, Chinn S. National study for health and growth social and family factors and obesity in primary school children. Ann Hum Biol 1982;9:131-45.

21 Locard E, Mamelle N, Billette A, Miginiac M, Munoz F, Rey S. Risk factors of obesity in a 5 year old population - parenta versus environmental factors. Int $\mathcal{F}$ Obes 1992;16:721-9.

22 Gortmaker SL, Must A, Sobol AM, Peterson K, Colditz GA, Dietz WH. Television viewing as a cause of increasing obesity among children in the United States, 1986-1990. Arch Pediatr Adolesc Med 1996;150:356-62.

23 Dietz W. Factors associated with childhood obesity. Nutrition 1991;7:290-1.

24 Dietz WH, Gortmaker SL. Do we fatten our children at the television set? Obesity and television viewing in children and adolescents. Pediatrics 1985;75:807-12.

25 Rolland-Cachera MF, Deheeger M, Akrout M, Bellisle F. Influence of macronutrients on adiposity development: a follow up study of nutrition and growth from 10 months to 8 years of age. Int 7 Obes 1995;19:573-8.

26 Sorensen TIA, Holst C, Stunkard AJ, Skovgaard LT. Correlations of body mass index of adult adoptees and their biological and adoptive relatives. Int F Obes 1992;16:227-36.

27 Serdula MK, Ivery D, Coates. RJ, Freedman DS, Williamson Serdula MK, Ivery D, Coates RJ, Freedman DS, Williamson
DF, Byers T. Do obese children become obese adults? A DF, Byers T. Do obese children become obese a
review of the literature. Prev Med 1993;22:167-77.

28 Power C, Lake JK, Cole TJ. Measurement and long-term health risks of child/adolescent fatness. Int $\mathcal{F}$ Obes 1997;21 507-26.

29 Power C, Lake JK, Cole TJ. Body mass index and height from childhood to adult life in the 1958 British birth cohort. Am 7 Clin Nutr 1997;66.

30 Butler NR, Bonham DG. Perinatal mortality. Edinburgh: Churchill Livingstone, 1963.

31 Ferri E. Life at 33: the fifth follow-up of the National Child Development Study. London: National Children's Bureau, 1993.
32 Power C, Moynihan C. Social class and changes in weightfor-height between childhood and early adulthood. Int $\mathcal{F}$ Obes 1988;12:445-53.

33 Knight I. The heights and weights of young adults in Great Britain. London: HMSO, 1984.

34 Must A, Dallal GE, Dietz WH. Reference data for obesity: 85th and 95th percentiles of body mass index $\left(\mathrm{wt} / \mathrm{ht}^{2}\right)$ and triceps skinfold thickness. Am f Clin Nutr 1991;53:839-46.

35 Kendall M, Stuart A. The advanced theory of statistics. London: Griffin, 1977:419.

36 Bennett N, Dodd T, Flatley J, Freeth S, Bolling K. The health of our nation: health survey for England 1993. London: Office of Population Censuses and Surveys, 1995:31-43.

37 Gulliford MC, Rona RJ, Chinn S. Trends in body mass index in young adults in England and Scotland from 1973 to 1988. F Epidemiol Community Health 1992;46:187-90.

38 Gortmaker SL, Dietz WH, Sobol AM, Wehler CA. Increasing pediatric obesity in the United States. Am f Dis Child 1987;141:535-40.

39 Shah M, Hannan PJ, Jeffery RW. Secular trend in body mass index in the adult population of three communities from the upper mid-western part of the USA: the Minnesota Heart Health Program. Int F Obes 1991;15:499-503.

40 Sorensen TIA, Price RA. Secular trends in body mass index among Danish young men. Int 7 Obes 1990;14:411-9.

41 Rice T, Bouchard C, Perusse L, Rao DC. Familial clustering of multiple measures of adiposity and fat distribution in the Quebec family study: a trivariate analysis of percent body fat, body mass index, and trunk-to-extremity skinfold ratio. Int $\mathcal{F}$ Obes 1995;19:902-8.

42 Wing RR, Epstein LH, Ossip DJ, LaPorte RE. Reliability and validity of self-report and observers' estimates of relative weight. Addict Behav 1979;4:133-40.

\title{
Birth weight and body fat distribution in adolescent girls
}

\author{
M Barker, S Robinson, C Osmond, D J P Barker
}

MRC Environmental Epidemiology Unit, University of

Southampton,

Southampton General Hospital, Southampton SO16 6YD

M Barker

S Robinson

C Osmond

D J P Barker

Correspondence to: Mary Barker.

\begin{abstract}
Objective-To examine the association between birth weight and body fat distribution in a group of adolescent girls.

Design-A total of 216 white girls who were born in Southampton had their heights, weights, waist and hip circumferences, and skinfold thicknesses measured when they were aged between 14 and 16 years.

Results-The girls who were smallest at birth, but who were fattest at time of measurement were the most centrally obese. In girls whose body mass index was above the median $\left(21 \mathrm{~kg} / \mathrm{m}^{2}\right)$, the subscapular to triceps skinfold ratio rose by $\mathbf{9 \%}$ for every kilogram decrease in birth weight. Among overweight girls, with a body mass index over 25 , the ratio rose by $\mathbf{2 7 \%}$ for every kilogram decrease in birth weight.

Conclusion-In adolescent girls, the tendency to store fat on the trunk rather than the limbs, seems to be programmed by growth in fetal life, and is most evident in those who are overweight.

(Arch Dis Child 1997;77:381-383)
\end{abstract}

Keywords: birth weight; adolescence; body fat distribution
Low weight at birth is associated with the development of non-insulin dependent diabetes and the insulin resistance syndrome in adult life. ${ }^{1}$ Central obesity is a component of this syndrome. This is one of the observations that has led to the hypothesis that non-insulin dependent diabetes and cardiovascular disease are 'programmed' by events in fetal life that lead to persisting changes in the body's structure and metabolic function.

A number of studies suggest that low birth weight is associated with a central pattern of fat distribution. Increased central fat deposition, indicated by a high ratio of subscapular to triceps skinfolds has been found in 7-12 year old children in the USA who were born small, ${ }^{2}$ and also in young adult Mexican-Americans. ${ }^{3}$ Higher waist circumference ${ }^{4}$ and higher waist to hip ratio ${ }^{56}$ have both been associated with low birth weight in adults. These findings suggest that impaired fetal growth leads to increased deposition of fat on the trunk in adult life. A recent case-control study of adolescents in the UK produced findings inconsistent with this hypothesis. ${ }^{7}$ There were no differences in the body fat distribution of low birthweight adolescent girls and boys and normal birthweight adolescent controls. ${ }^{7}$ Differences in study design make it difficult to 